\title{
An investigation into the effect of cementation on self- heating of backfill
}

\author{
A Zarassi McGill University, Canada \\ FP Hassani McGill University, Canada
}

\begin{abstract}
The use of high sulphide content mine tailings as backfill could pose technical and environmental challenges during mining operations or the post-mining cycle. This paper describes one of these challenges: the self-heating of high sulphide content backfills, and proposes a mitigation method involving the use of different amounts of binders and additives. Tailings rich in sulphide minerals, and in particular pyrrhotite, may self-heat, defined as the spontaneous oxidation of materials resulting in excessive heat generation. This phenomenon has led to mine fires, elevated toxic gas levels, oxygen depletion in the stopes, acid mine drainage and even mine closure in some cases. The self-heating cycle can be described in three stages, defined by increasing heating rates: stage $A$ from ambient temperature to $100^{\circ} \mathrm{C}$, at which point free moisture is driven off; stage $B$ continues to $350-400^{\circ} \mathrm{C}$ (the ignition point of sulphides) if sustained by the reactions; and Stage $C$ starts at the ignition point, and effectively represents roasting of the material. A unique apparatus for measuring stage $A$ and stage $B$ self-heating rates, which was originally developed at the Noranda Technology Centre in the 1980s, and now resides at McGill University, was used for this work. Results are reported as self-heating capacity (SHC) for backfill samples (joules/gram). Interpretation of SHC values is done by using a risk-assessment chart that delineates five regions of increasing risk. The experimental program reported here involved adding different amounts of cement, slag and sodium silicate to high-pyrrhotite tailings to investigate the mitigating effect of cementation on self-heating. Findings clearly demonstrate that cementation significantly reduces the SHC values of backfill samples and effectively removes their associated data points from the high risk region in the assessment chart. In addition, the SHC values are highly sensitive to the amount of binders and additives added to the backfill.
\end{abstract}

\section{1} Introduction

Paste fill is widely used as mine fill for tailings disposal and cost reduction (Hassani \& Archibald 1998; Hassani \& Bois 1992). However, tailings with high sulphide content, especially those containing pyrrhotite, may experience auto-oxidation, also known as self-heating. The earliest report of the phenomenon is from the Sullivan Mine, where the serious problem of self-heating of broken sulphide ore left in the stopes was documented (O'Brien \& Banks 1926). Since then, self-heating of sulphides has been defined, studied and investigated by many researchers (Lukaszewski 1969; Farnsworth 1977; Good 1977; Rosenblum \& Spira 1995; Rosenblum et al. 2001; Wu \& Li 2005; Navarra et al. 2010; Somot \& Finch 2010).

Sulphide mixtures may self-heat in the presence of moisture and oxygen. If the heat generated in the exothermic reactions is not dissipated, temperatures can reach the ignition point of the sulphide mixture, typically $350-400^{\circ} \mathrm{C}$. Self-heating problems are manifested as fire hazards, dust explosions, excessive heat, $\mathrm{SO}_{2}$ fumes, ore alteration and effects on explosives (Ninteman 1978).

"If the minefill contains a large quantity of reactive sulphide and the proper moisture content, accelerated oxidation may result in heat and sulfur dioxide fumes, acid mine drainage and even the reduction of oxygen supply in stopes. All cements oxidize during the curing process to give off heat; sulphide material may spontaneously oxidize also, depending on the sulphide reactivity, the fineness and proportion of sulphide cementing agents present, as well as the balance between the heat liberated and the heat dissipated during oxidation." Ninteman (1978) 
Pure sulphide minerals, namely pyrite, sphalerite and galena, will not self-heat. Pyrrhotite seems to be the exception (Payant \& Finch 2010) and therefore is of great concern in tailings mixtures designated for mine fill. The pyrrhotite content must be kept below $10 \%(\mathrm{wt})$ in mine fill to prevent self-heating (Rosenblum \& Spira 1995; Bernier \& Li 2003). This value appears to be the 'rule-of-thumb' in the industry (Zarassi et al. 2011).

Preliminary attempts made by the authors to quantify self-heating of high pyrrhotite content backfills showed that the contents of pyrrhotite, as well as cementing binders and sodium silicate (a hygroscopic agent), are the main factors that influence self-heating of backfills and manipulation of these factors represents an approach to mitigate the self-heating problem (Zarassi et al. 2011).

\section{$2 \quad$ Self-heating mechanism and apparatus}

As shown in Figure 1, self-heating occurs in three stages (A-C). Stage A occurs from ambient temperature to $100^{\circ} \mathrm{C}$ in the presence of moisture and oxygen. Exothermic oxidation of the mineral results in the formation of elemental sulphur (Rosenblum \& Spira 1995). Subsequent studies have shown the importance of an acidic environment, and the likelihood of $\mathrm{H}_{2} \mathrm{~S}$ oxidation being an important contributor to the sequence of reactions contributing to self-heating (Wang et al. 2009; Somot \& Finch 2010). Stage A also has an electrochemical basis (Payant \& Finch 2010$)$. During stage $B\left(100^{\circ} \mathrm{C}\right.$ to approximately $\left.350^{\circ} \mathrm{C}\right)$, it is postulated that the sulphur formed in stage $A$ oxidises to $\mathrm{SO}_{2}$ (Rosenblum \& Spira 1995). Stage $\mathrm{C}$ is at temperatures above the ignition point of the sulphides $\left(>350^{\circ} \mathrm{C}\right)$, and is effectively the stage at which the material roasts. The rate of temperature rise $\left({ }^{\circ} \mathrm{C} / \mathrm{h}\right)$ increases by at least an order of magnitude in each successive stage.

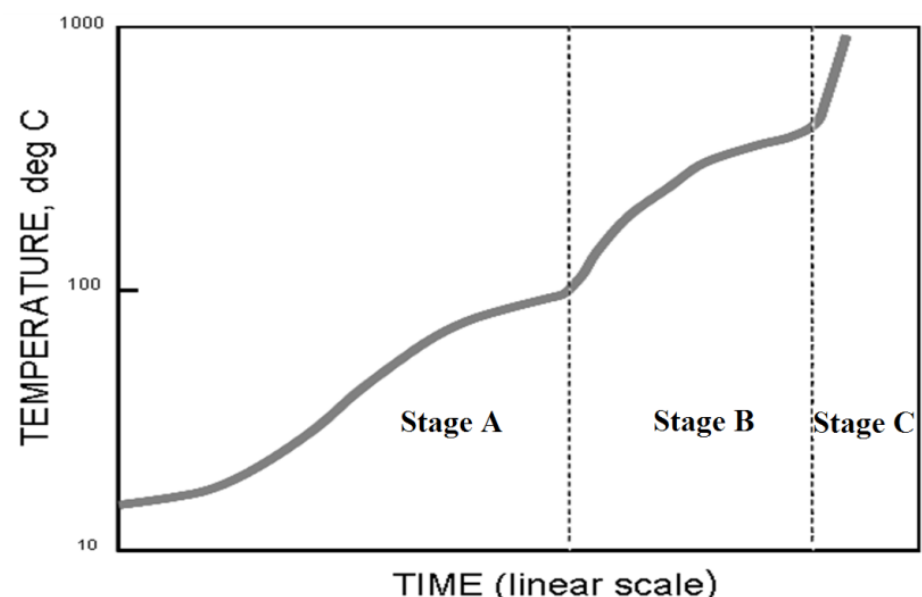

Figure 1 Schematic of temperature rise versus time for self-heating stages A-C (Rosenblum et al. 2001)

The standard self-heating protocol of Rosenblum et al. (2001) was adopted for quantitative measurement of self-heating activity of sulphide backfills (Zarassi et al. 2011). What is in essence an accelerated weathering test is run on $500 \mathrm{~g}$ samples in the presence of $6 \%$ moisture at elevated temperatures of $70^{\circ} \mathrm{C}$ (stage $\mathrm{A}$ ) and $140^{\circ} \mathrm{C}$ (stage $\mathrm{B}$ ), with periodic injections of air every $5 \mathrm{~h}$ for $15 \mathrm{~min}$. Thermocouples record the rate of temperature rise at each air injection and values are averaged and converted to provide a value of self-heating capacity (SHC) in joules/gram for each stage (Figure 2). The standardised test conditions run for $48 \mathrm{~h}$ in each stage. Typically the self-heating rate passes through a maximum during weathering in stage $\mathrm{A}$, and then decreases as the moisture evaporates or sulphides are consumed by oxidation (Figure 3 ). Simultaneously, elemental sulphur is formed and its content continues to increase as long as moisture and sulphide mineral remains in the sample. In stage $B$, the self-heating rate increases to a sharp peak while the elemental sulphur formed in stage $\mathrm{A}$ is oxidised to $\mathrm{SO}_{2}$. 


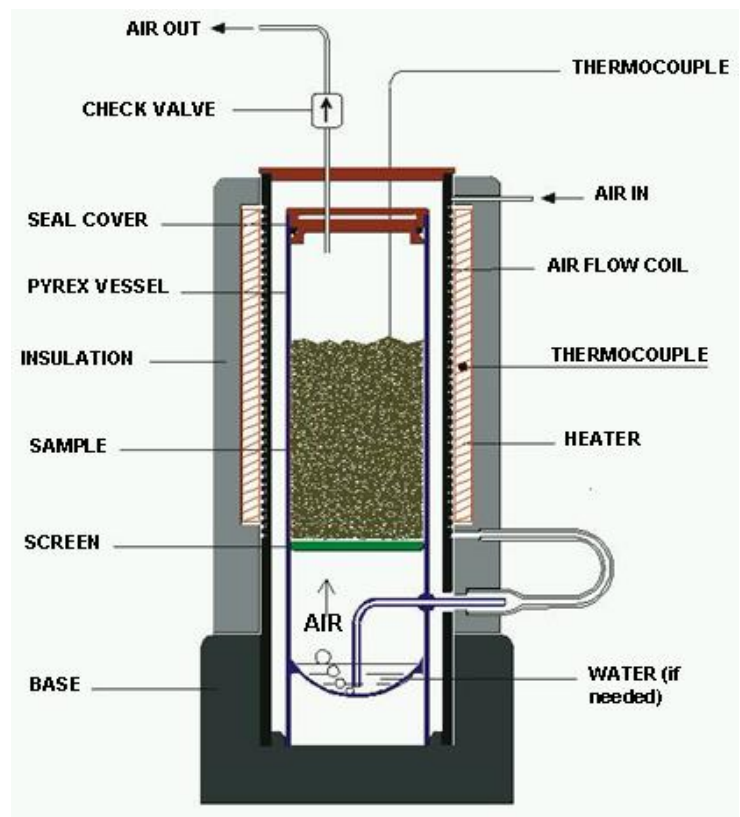

Figure 2 Self-heating apparatus (Rosenblum et al. 2001)

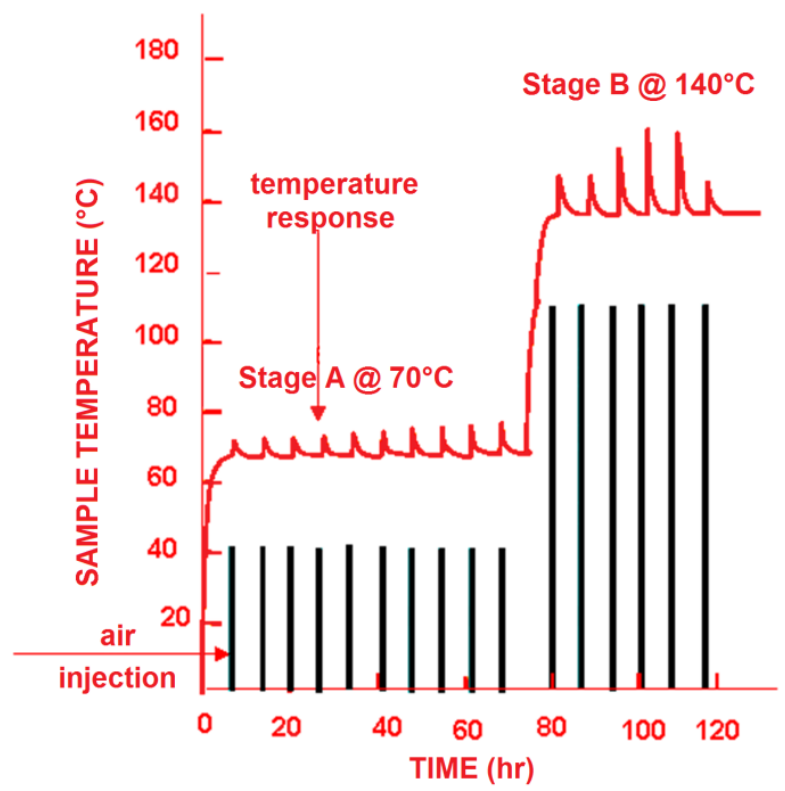

Figure 3 Typical responses at stages A and B (Rosenblum et al. 2001)

Results are reported as stage B SHC (y-axis) versus Stage A SHC (x-axis), in what is known as a 'risk assessment chart' having five regions (Figure 4). The chart regions are based on a large database for sulphide materials displaying a wide range of self-heating behaviours in the field. Region 5, termed recommend preventive action, is the highest risk region. Materials falling in this region will self-heat if the right conditions of temperature, moisture, available oxygen and time are present. Region 4, termed recommend monitoring, is an intermediate or 'grey' area where self-heating might occur. Materials in region 2 may self-heat at stage $A$ but doesn't go beyond $100^{\circ} \mathrm{C}$. Materials in regions 1 and 3 do not present a high risk of self-heating in stage $A$ and are acceptable from a mining point of view. Materials in Region 1 are totally inactive whereas those in region 3 will be inactive, if not exposed to a high heat source (the expected situation in an operating mine). 


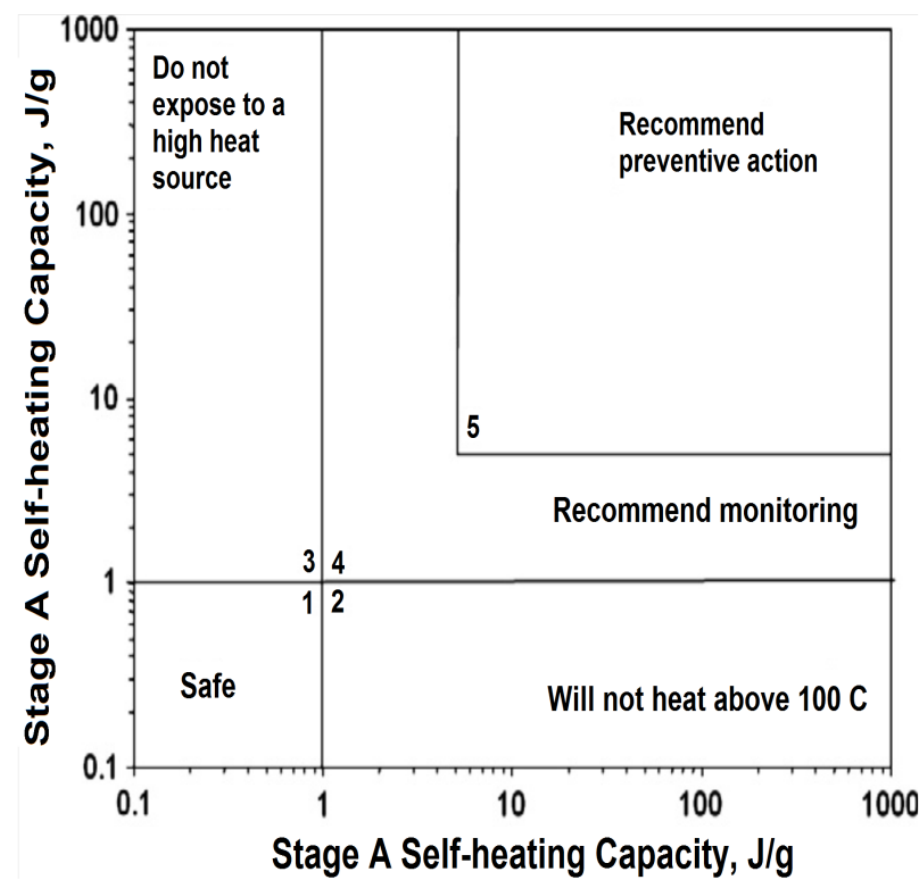

Figure 4 Risk assessment chart for the self-heating of sulphides (Rosenblum et al. 2001)

\section{$3 \quad$ Factors that influence self-heating}

Fundamental studies by Ninteman (1978) and Rosenblum and Spira (1995) elucidated important physical and chemical factors that influence self-heating. These are summarised below (Zarassi et al. 2011):

- Mineralogical composition (minerals and their relative proportions),

- degree of weathering or oxidation,

- $\mathrm{pH}$,

- chemical additives,

- surface chemistry,

- moisture content and humidity,

- temperature,

- porosity and permeability,

- particle size distribution (surface area),

- ventilation and access to air (oxygen); and

- ability to dissipate heat.

The tendency to oxidise is a complex function of mineral composition, among other factors. Sulphides are ranked according to their tendency to oxidise. Pyrrhotite is ranked highly (Klassen \& Mokrousov 1963) and under variable moisture content, is the most reactive mineral (Lukaszewski 1969). Studies of the electrochemical nature of mineral oxidation, when dissimilar minerals are in contact, show that galena, sphalerite, covellite and energite oxidise 8-20 times faster in the presence of pyrite (Anderson 1930). Recent studies show that individually, these sulphide minerals do not self-heat, whereas pyrrhotite does (Payant 2010; Wang et al. 2009).

Initiation of self-heating, i.e. stage A, requires an acidic environment (Wang et al. 2009; Somot \& Finch 2010), which contributes to mineral oxidation and possible $\mathrm{H}_{2} \mathrm{~S}$ generation. It is clear that moisture is also an essential factor for stage $A$ to occur, in particular a moisture content of approximately $3-8 \%(w t)$ in the 
mineral mixtures (Ninteman 1978; Rosenblum \& Spira 1981). Cyclic weathering, i.e. fluctuating wet and dry conditions, as may be found in an underground environment, also contributes to the risk of self-heating (Lukaszewski 1969).

The oxidation rate of pyrite doubles for every $10^{\circ} \mathrm{C}$ rise in temperature, in the range of $30-60^{\circ} \mathrm{C}$ (Enderlin 1973). Quantitative studies show that reactions accelerate rapidly above $30^{\circ} \mathrm{C}$ (Rosenblum \& Spira 1995). This means that the underground mining environment, both in terms of humidity and temperature, may highly favour spontaneous oxidation of sulphides (Zarassi et al. 2011).

The oxidation rate increases as particle size decreases, and as porosity and permeability increase (Lukaszewski 1969). Also, a somewhat oxygen-deficient environment of around 5\% (compared to normal 21\%) results in maximum heating rates (Wang et al. 2009). This may help to explain why self-heating tends to initiate some distance below the surface in piles of mineral concentrates (Rosenblum et al. 2001).

\section{$4 \quad$ Mitigation methods}

Based on the influencing factors discussed in Section 3, a variety of mitigating methods has been suggested (Rosenblum \& Spira 1995). For backfill purpose, these methods should be cost-effective and environmentally acceptable, and should not interfere with other activities in the mine (Zarassi et al. 2011). These considerations eliminate some of the suggested methods, such as cooling down the rock by chilled air, limiting the oxygen supply by inert gas, flooding in water or removing fine particles from tailings.

Controlling pyrrhotite content to below $10 \%$ is a practical and practiced method. If pyrrhotite-rich tailings are diluted with non-sulphide tailings to a pyrrhotite content below $10 \%$, the self-heating rate is significantly reduced (Rosenblum \& Spira 1995; Zarassi et al. 2011) (Figure 5). This guideline has been formally adopted by several mines utilising paste fill technology (Bernier \& Li 2003).

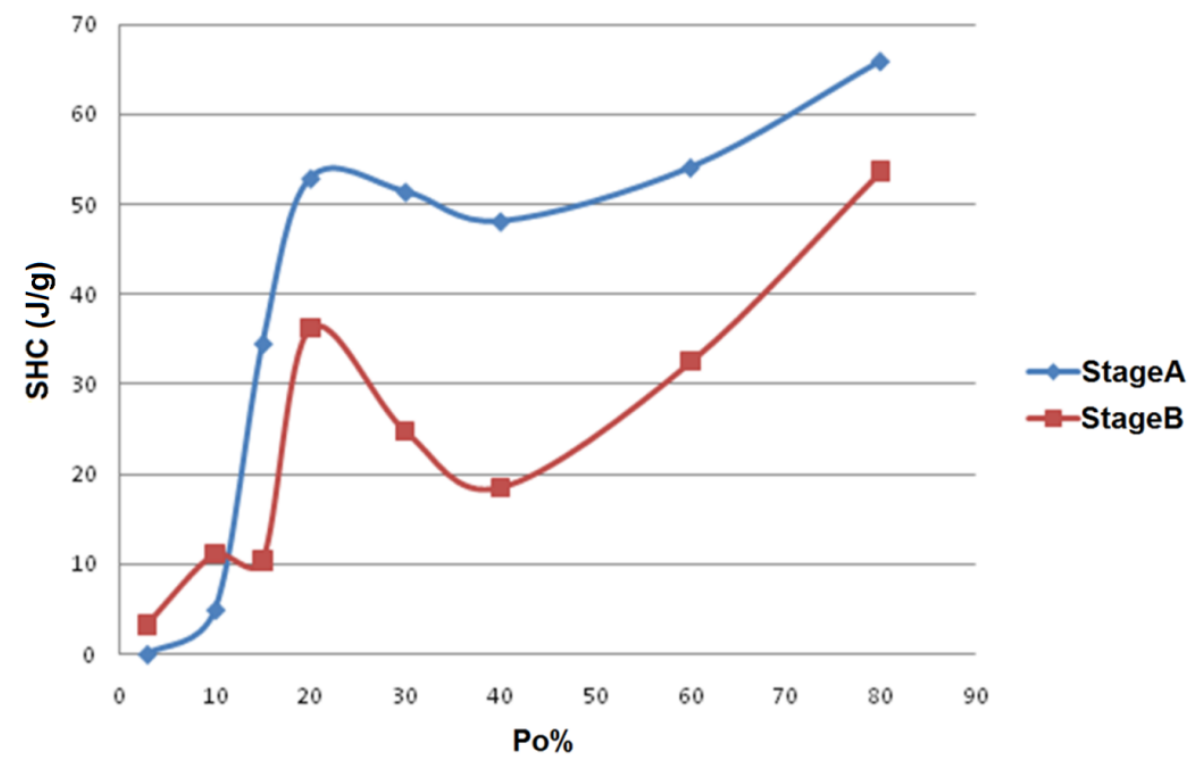

Figure 5 Effect of pyrrhotite content (Po\%) on SHC of tailings (Zarassi et al. 2011)

If controlling of the pyrrhotite content is not possible, or if other mineral combinations in sufficient quantity are responsible for the self-heating, other mitigation options are suggested (Zarassi et al. 2011):

- Limiting the oxygen supply by coating the mineral surface with suitable chemicals.

- Neutralising the acid with a suitable additive.

- changing chemical reactions by appropriate chemical additives. 
These methods have been investigated by Zarassi et al. (2011) and preliminary results show that $5 \%$ binder, a mixture of alkali slag and Portland cement at a 9:1 ratio, and 1\% sodium silicate added to high pyrrhotite content tailings and ores significantly and effectively reduces their self-heating activity (Figures 6 and 7).

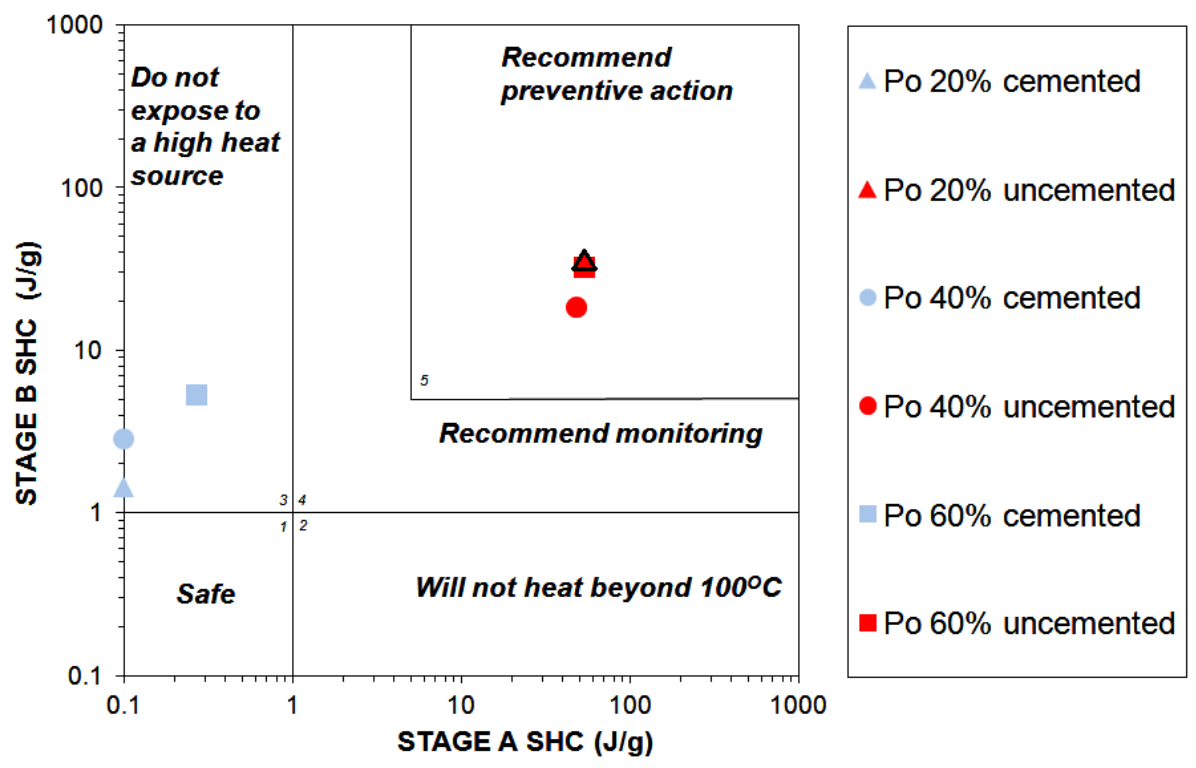

Figure 6 Risk assessment chart showing cementation effect on SHC for tailings with 20, 40 and $60 \%$ pyrrhotite $(\mathrm{Po})$ content

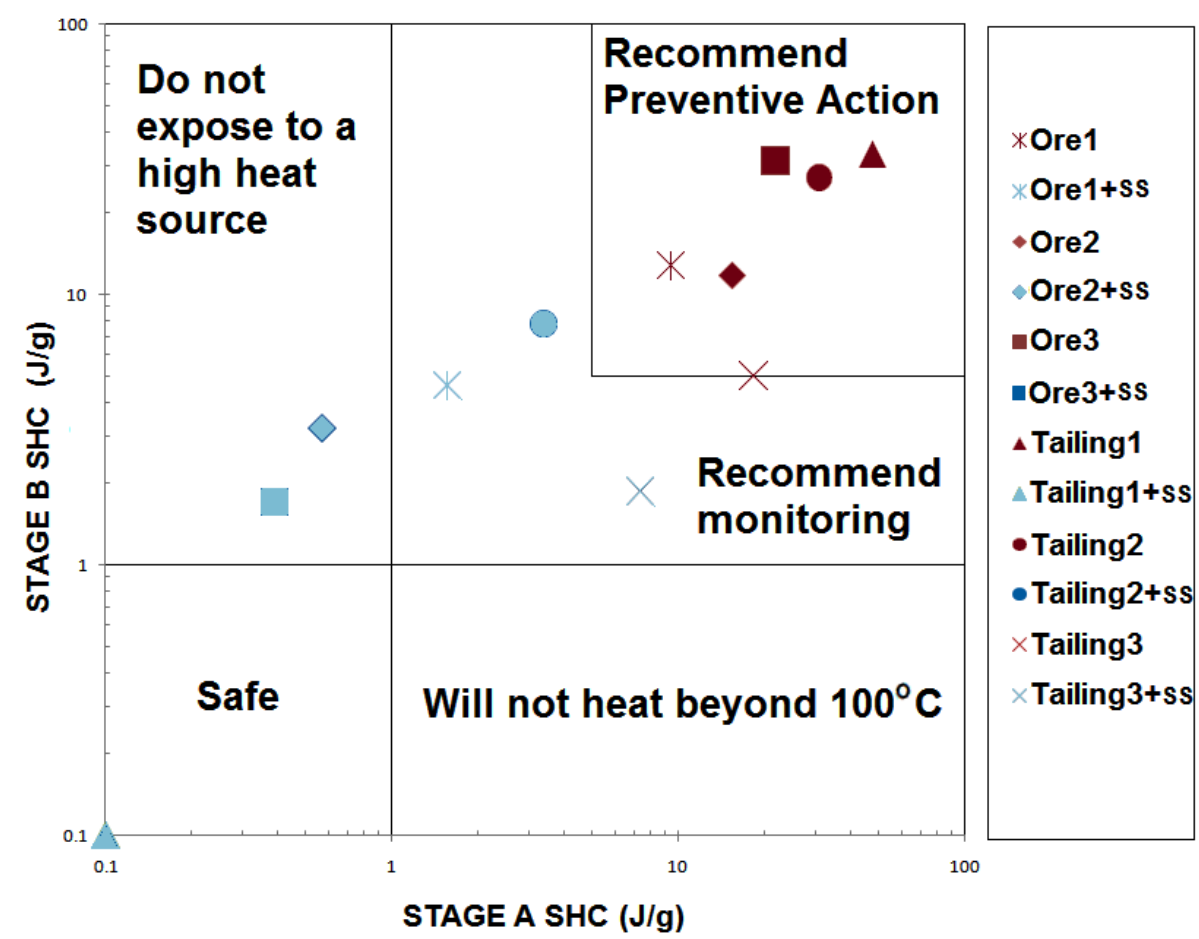

Figure 7 Risk assessment chart showing effect of sodium silicate on SHC of tailings and ores

\section{$5 \quad$ Sample preparation and tests results}

The work reported here is an investigation into the effect of different amounts of binder and sodium silicate on self-heating of backfill. A pyrrhotite-rich tailings (75\%) was selected and six recipes were designed consisting of two binder contents ( 2 and $4 \%$ binder made of a slag and Portland cement at a 9:1 ratio) and three sodium silicate binder additive contents per recipe (0, 0.3 and $0.5 \%)$ (Table 1$)$. Sodium 
silicate at 0.3 and $0.5 \%$ has been found to be optimal for reducing setting time, without compromising the uniaxial compressive strength values (Hassani et al. 2007; Kermani et al. 2009). Finally, to test the effect of pyrrhotite content and to compare with previous studies, two extra samples with $20 \%$ added aggregate were designed (Table 1). The slag is provided by Canada Cement Lafarge and sodium silicate is from National Silicate Inc.

Table 1 Sample recipe

\begin{tabular}{|c|c|c|c|c|}
\hline \multirow{2}{*}{$\begin{array}{l}\text { Total Po } \\
\text { content }\end{array}$} & \multicolumn{2}{|c|}{ Blend } & \multirow{2}{*}{$\begin{array}{c}\text { Binder } \\
\text { (slag:cement - 9:1) }\end{array}$} & \multirow{2}{*}{$\begin{array}{l}\text { Sodium } \\
\text { silicate }\end{array}$} \\
\hline & 75\% Po tailings & Aggregate & & \\
\hline $75 \%$ & $100 \%$ & $0 \%$ & $2 \%$ & $0.0 \%$ \\
\hline $75 \%$ & $100 \%$ & $0 \%$ & $2 \%$ & $0.3 \%$ \\
\hline $75 \%$ & $100 \%$ & $0 \%$ & $2 \%$ & $0.5 \%$ \\
\hline $75 \%$ & $100 \%$ & $0 \%$ & $4 \%$ & $0.0 \%$ \\
\hline $75 \%$ & $100 \%$ & $0 \%$ & $4 \%$ & $0.3 \%$ \\
\hline $75 \%$ & $100 \%$ & $0 \%$ & $4 \%$ & $0.5 \%$ \\
\hline $60 \%$ & $80 \%$ & $20 \%$ & $2 \%$ & $0.0 \%$ \\
\hline $60 \%$ & $80 \%$ & $20 \%$ & $4 \%$ & $0.0 \%$ \\
\hline
\end{tabular}

Samples were cured for 28 days at $22^{\circ} \mathrm{C}$ and a relative humidity of $85 \%$. They were then broken and ground to powder to simulate the worst case scenario of paste filled stope material breaking or sloughing-off the face (Zarassi et al. 2011). Finally, they were dried in a vacuum oven and $6 \%$ moisture was added before testing with the self-heating apparatus and standard protocol described previously (Rosenblum et al. 2001). SHC results of tested samples are presented in Table 2 and Figure 8.

Table 2 Self-heating tests results

\begin{tabular}{ccccc}
\hline \multirow{2}{*}{$\begin{array}{c}\text { Pyrrhotite } \\
\text { content }\end{array}$} & \multirow{2}{*}{$\begin{array}{c}\text { Binder } \\
\text { (slag:cement - 9:1) }\end{array}$} & $\begin{array}{c}\text { Sodium } \\
\text { silicate }\end{array}$ & \multicolumn{2}{c}{ SHC (j/g) } \\
\cline { 4 - 5 } & $2 \%$ & $0.0 \%$ & 39.1 & 63.4 \\
$75 \%$ & $2 \%$ & $0.3 \%$ & 44.5 & 0.0 \\
$75 \%$ & $2 \%$ & $0.5 \%$ & 21.2 & 0.0 \\
$75 \%$ & $2 \%$ & $0.0 \%$ & 21.4 & 12.9 \\
$60 \%$ & $4 \%$ & $0.0 \%$ & 2.3 & 4.0 \\
$75 \%$ & $4 \%$ & $0.3 \%$ & 1.7 & 3.4 \\
$75 \%$ & $4 \%$ & $0.5 \%$ & 0.0 & 5.9 \\
$75 \%$ & $4 \%$ & $0.0 \%$ & 0.0 & 9.7 \\
$60 \%$ & & & & \\
\hline
\end{tabular}




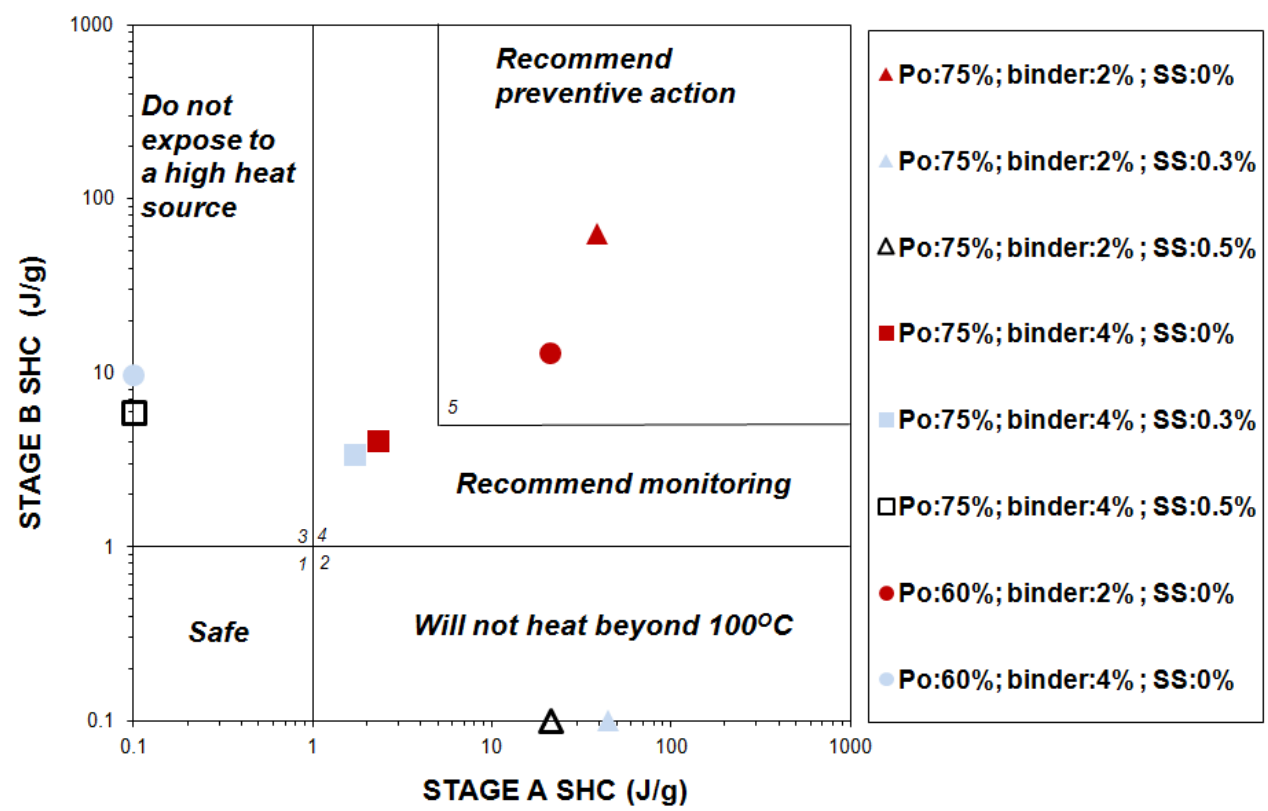

Figure 8 Risk assessment chart for tested samples with different pyrrhotite content (Po\%) and sodium silicate (SS)

\section{Cementation effect}

"Cementing tailings to produce paste fill may have the added benefit of reducing the available surface area of the sulphides and restrict oxygen access in such a way as to reduce self-heating activity. Moreover, cementing materials, such as Portland cement and slag, may contribute alkali components to the mixture thereby neutralizing some of the acidity generated by the sulphides and water, interrupting what is thought to be one of the key reactions in the self-heating sequence" Zarassi et al. (2011).

As described in Section 5, 2 and $4 \%$ binder were added to the tailings blends. Results of the current experiment, along with those from a previous study on uncemented samples (Zarassi et al. 2011), are presented in Table 3 and Figures 9 and 10.

Table 3 Self-heating tests results for cemented versus uncemented tailings

\begin{tabular}{cccc}
\hline \multirow{2}{*}{$\begin{array}{c}\text { Pyrrhotite } \\
\text { content }\end{array}$} & \multirow{2}{*}{$\begin{array}{c}\text { Binder } \\
\text { (slag:cement - 9:1) }\end{array}$} & \multicolumn{2}{c}{ SHC (J/g) } \\
\cline { 3 - 4 } & Stage A & Stage B \\
\hline $75 \%$ & $0 \%$ & 37.3 & 33.2 \\
$75 \%$ & $2 \%$ & 39.1 & 33.4 \\
$75 \%$ & $4 \%$ & 2.3 & 4.0 \\
$60 \%$ & $2 \%$ & 21.4 & 12.9 \\
$60 \%$ & $4 \%$ & 0.0 & 9.7 \\
\hline
\end{tabular}




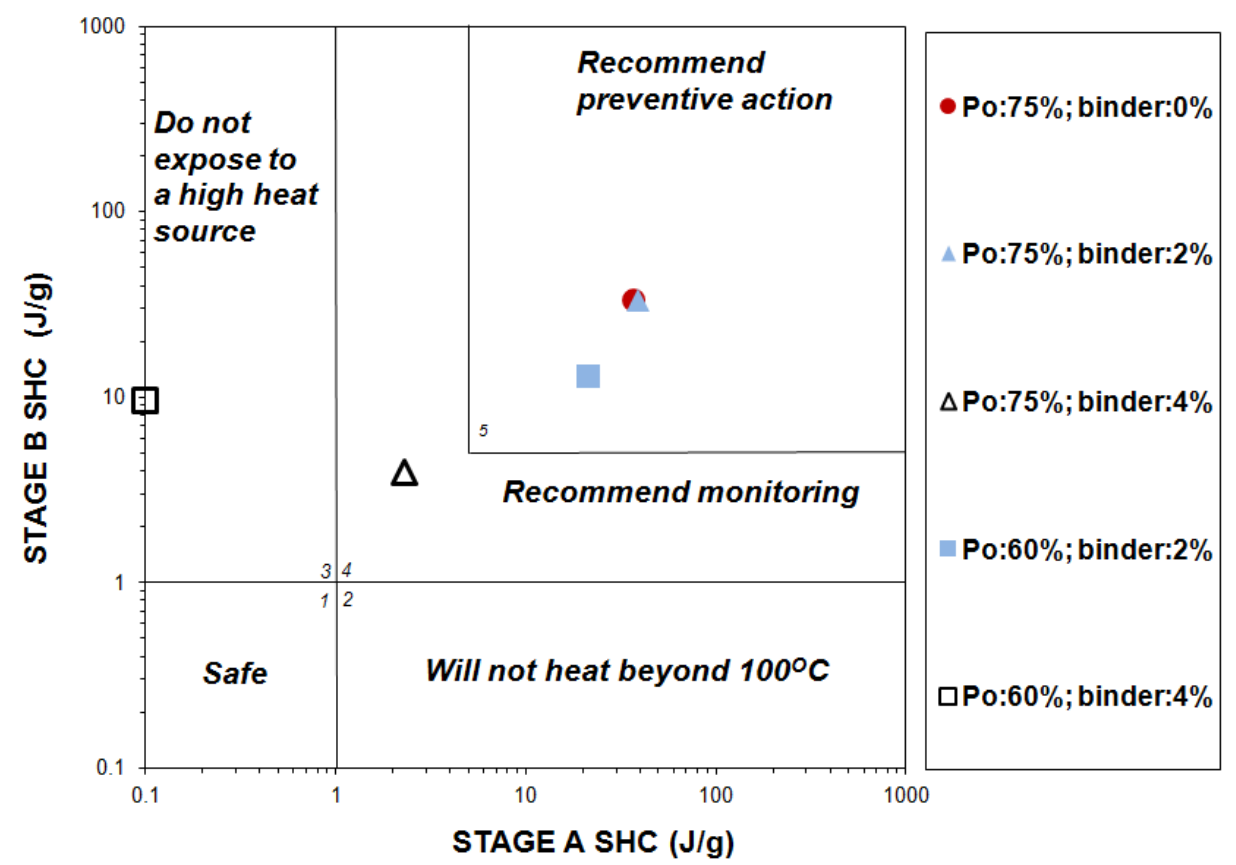

Figure 9 Risk assessment chart showing effect of 0,2 and $4 \%$ binder on SHC of tailings with 60 and $75 \%$ pyrrhotite (Po)

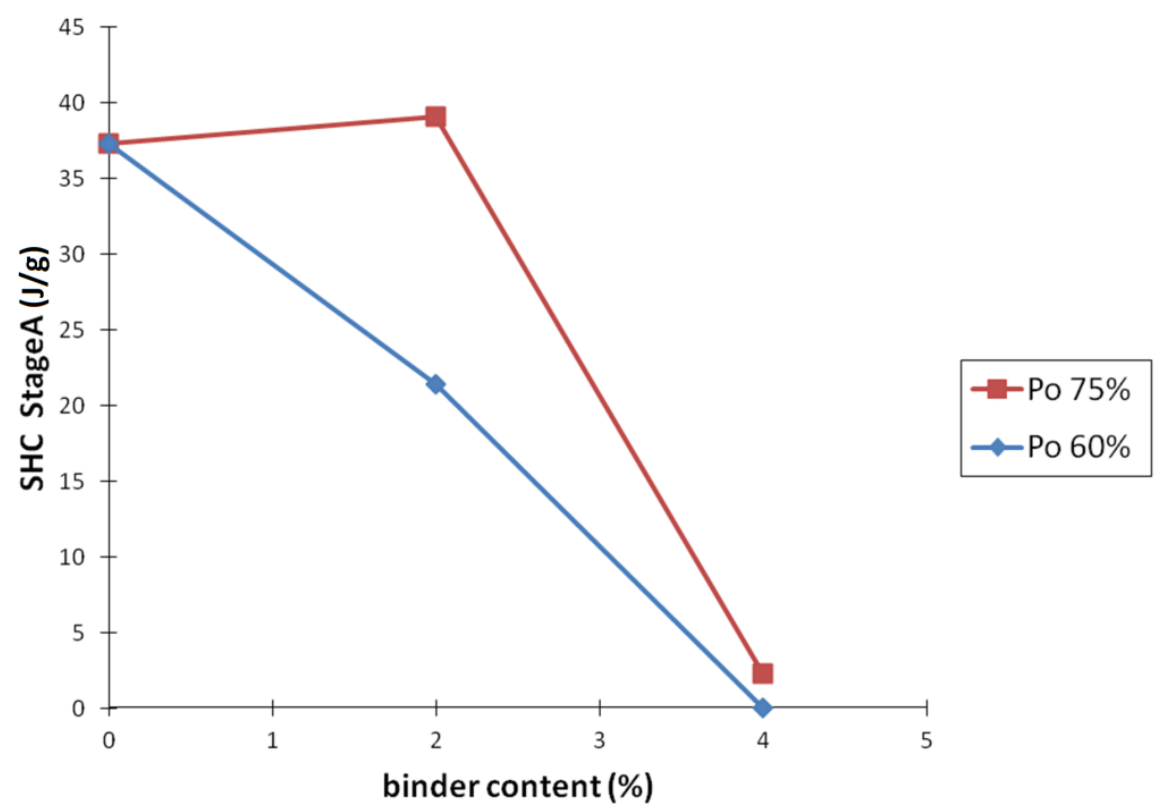

Figure 10 Effect of 0,2 and $4 \%$ binder content on SHC of tailings with 60 and $75 \%$ pyrrhotite (Po)

These results show that SHC is highly dependent on the pyrrhotite content and binder amount. As mentioned in Section 2, from the mining point of view, only regions 1 and 3 of the risk assessment chart are acceptable. For a $75 \%$ pyrrhotite content, $2 \%$ binder of (90:10 slag:cement) is totally insufficient and has no effect on SHC, whereas $4 \%$ binder has a significant, though not completely satisfactory, role in the mitigation process. For $60 \%$ pyrrhotite content, $2 \%$ binder reduces SHC but it remains in region 5 , which is a dangerous area. By comparison, $4 \%$ binder is completely effective at mitigating self-heating. The previous study used $5 \%$ of the same binder and up to $80 \%$ pyrrhotite content (Zarassi et al. 2011). If strength criteria are satisfied, $4 \%$ binder is proposed as a basis for self-heating mitigation of high pyrrhotite content backfills. 


\section{Sodium silicate effect}

As explained in Sections 3 and 4, controlling moisture content with a hygroscopic agent is an obvious method to reduce the risk of self-heating in stage A. Preliminary studies with sodium silicate show promising results (Zarassi et al. 2011).

Sodium silicate is the common name for sodium metasilicate $\left(\mathrm{Na}_{2} \mathrm{SiO}_{3}\right)$, also known as water glass or liquid glass. Molten sodium carbonate and silicon dioxide react to form sodium silicate and carbon dioxide (Greenwood \& Earnshaw 1997) according to:

$$
\mathrm{Na}_{2} \mathrm{CO}_{3}+\mathrm{SiO}_{2} \rightarrow \mathrm{Na}_{2} \mathrm{SiO}_{3}+\mathrm{CO}_{2} \mathrm{Na}_{2} \mathrm{CO}_{3}+\mathrm{SiO}_{2} \rightarrow \mathrm{Na}_{2} \mathrm{SiO}_{3}+\mathrm{CO}_{2}
$$

Anhydrous sodium silicate (Figure 11) contains a chain polymeric anion composed of corner-shared $\left(\mathrm{SiO}_{4}\right)$ tetrahedral, and not a discrete $\mathrm{SiO}_{3}{ }^{2-}$ ion (Greenwood \& Earnshaw 1997) (Figure 11). In addition to the anhydrous form, there are a number of hydrates with the formulae $\mathrm{Na}_{2} \mathrm{SiO}_{3} \cdot \mathrm{nH}_{2} \mathrm{O}$. Commercially, sodium silicate is available in both aqueous solution and in solid form and has been studied as a binder additive in backfill cementing by Spearing and Smart (1990), Hassani et al. (2007) and Kermani et al. (2009).

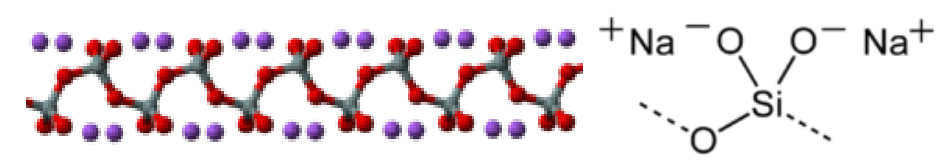

Figure 11 Schematic of sodium silicate polymeric chain

Sodium silicate is stable in neutral and alkaline solutions. In acidic solutions, the silicate ion reacts with hydrogen ions, providing some neutralisation capability, but ultimately the compound breaks down. Therefore, it is suggested to be used as an additive in combination with other alkaline additives (Zarassi et al. 2011).

As described in Section 5, sodium silicate at 0.3 and $0.5 \%$ were added to high pyrrhotite content tailings along with cementing binders. At $0.3 \%$ sodium silicate, the effect on SHC is completely dominated by the effect of the binder, however, at $0.5 \%$ sodium silicate, the mitigating potential is observed (Table 4 ).

Table 4 Self-heating tests results for sodium silicate augmented samples

\begin{tabular}{ccccc}
\hline \multirow{2}{*}{$\begin{array}{c}\text { Pyrrhotite } \\
\text { content }\end{array}$} & \multirow{2}{*}{$\begin{array}{c}\text { Binder } \\
\text { (slag:cement - 9:1) }\end{array}$} & Sodium & silicate & \multicolumn{2}{c}{ SHC (J/g) } \\
\cline { 4 - 5 } & & Stage A & Stage B \\
\hline $75 \%$ & $2 \%$ & $0.0 \%$ & 39.1 & 63.4 \\
$75 \%$ & $2 \%$ & $0.3 \%$ & 44.5 & 0.0 \\
$75 \%$ & $2 \%$ & $0.5 \%$ & 21.2 & 0.0 \\
$75 \%$ & $4 \%$ & $0.0 \%$ & 2.3 & 4.0 \\
$75 \%$ & $4 \%$ & $0.3 \%$ & 1.7 & 3.4 \\
$75 \%$ & $4 \%$ & $0.5 \%$ & 0.0 & 5.9 \\
\hline
\end{tabular}

As is shown in Figures 12 and 13 , for $2 \%$ binder content, $0.5 \%$ sodium silicate reduces the stage A SHC by half. In the case of $4 \%$ binder, $0.5 \%$ sodium silicate completely mitigates SHC of Po $75 \%$ backfill. 


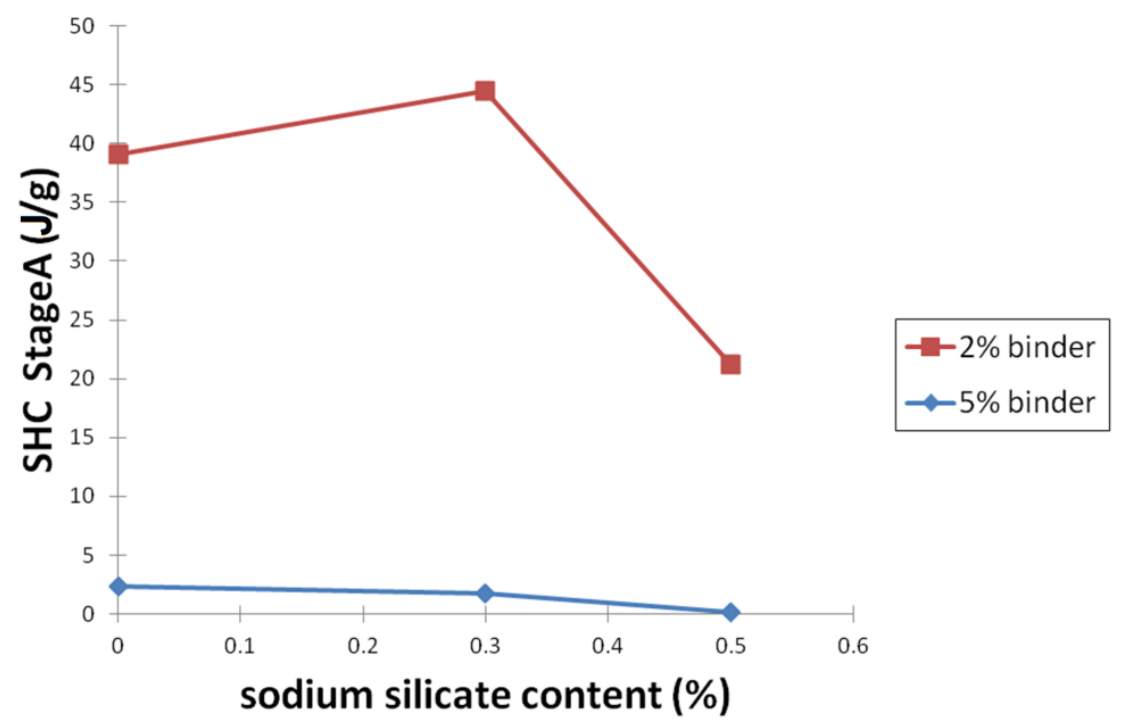

Figure 12 Effect of $0,0.3$ and $0.5 \%$ sodium silicate on SHC of tailings with $75 \%$ pyrrhotite

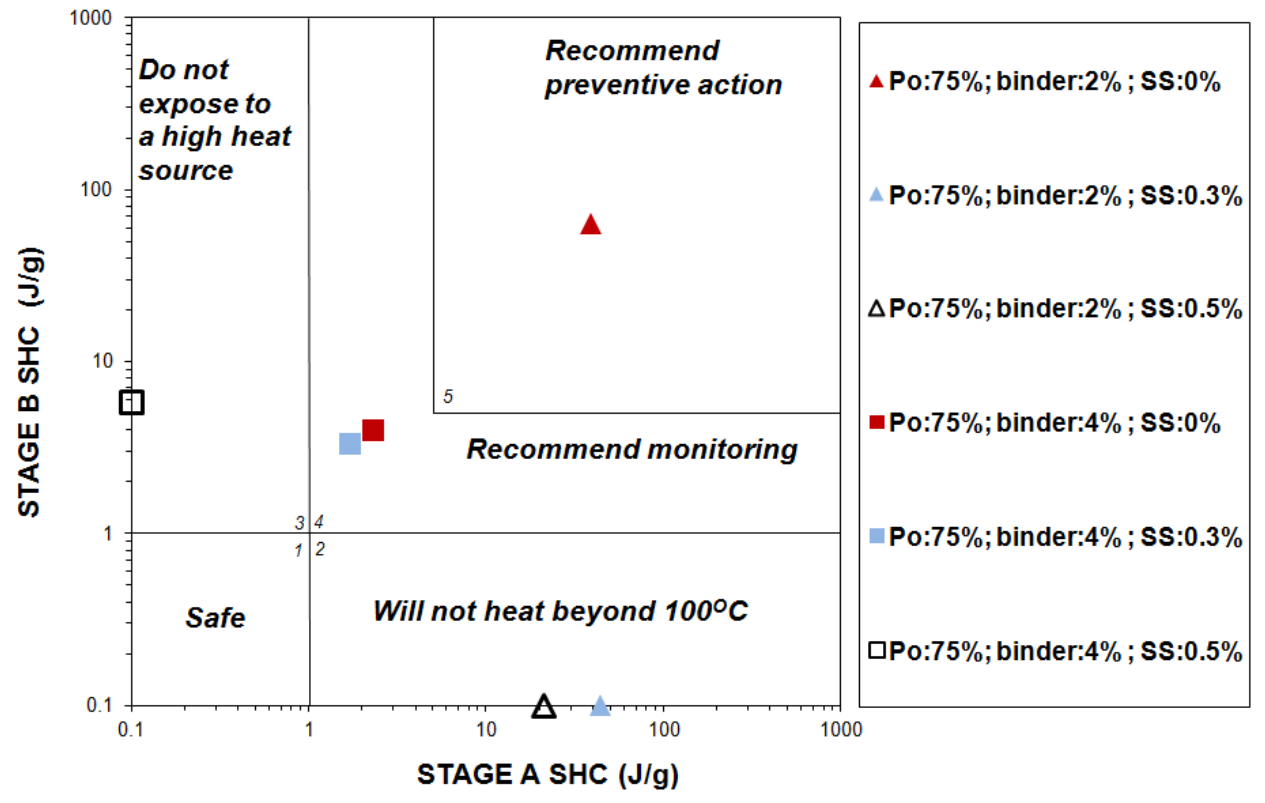

Figure 13 Risk assessment chart showing effect of $0,0.3$ and $0.5 \%$ sodium silicate on SHC of tailings

\section{Conclusions}

This work demonstrated the effect of cementation and sodium silicate addition on the self-heating of high sulphide content backfill. The standard test protocol of Rosenblum et al. (2001) was used to quantify self-heating behaviour. Results show that for high pyrrhotite content backfill (up to Po 75\%), the binder (9:1 mixture of slag:cement) content should be at least $4 \%$ to avoid possible self-heating problems. In addition, sodium silicate as a hygroscopic agent needs to be added at $0.5 \%$ to the binder to keep the stage A SHC as low as zero. At $2 \%$ binder content, $0.5 \%$ sodium silicate reduces stage A SHC by half, although it is still too high to be considered safe.

This work is ongoing to evaluate binder contents between 2 and $4 \%$, tailings with different pyrrhotite contents and different binder types. 


\section{Acknowledgement}

The authors acknowledge the financial contribution of Natural Sciences and Engineering Research Council of Canada (NSERC). The authors are also grateful for the financial and technical support of Vale and National Silicate Inc. This research is facilitated by the logistic support and professional advice of Ike Isagon. The assistance and contributions of Professor Jim Finch and Frank Rosenblum, as well as other graduate and undergraduate students at McGill University, are very much appreciated.

\section{References}

Anderson, AL 1930, 'The incipient oxidation of galena', Economic Geology, vol. 25, no. 5, pp. 528-42.

Bernier, LR \& Li, M 2003, 'High temperature oxidation (heating) of sulfidic paste backfill: A mineralogical and chemical perspective', in G. Spiers (ed.), Proceedings of the 3rd Mining and the Environment Conference, Canadian Land Reclamation Association, Calgary, on CD-ROM.

Enderlin, WI 1973, 'Evaluating underground heat sources in deep mines', master thesis, Montana College of Mineral Science and Technology.

Farnsworth, DJM 1977, 'Introduction to and background of sulphide fires in pillar mining at the Sullivan mines', CIM Bulletin, vol. 70, no. 782, pp. 65-71.

Good, BH 1977, 'The oxidation of sulphide minerals in the Sullivan mine', CIM Bulletin, vol. 70, no. 782, pp. 83-8.

Greenwood, N \& Earnshaw, A 1997, Chemistry of the elements, 2nd edn, Butterworth-Heinemann, Oxford, Oxfordshire.

Hassani, FP \& Bois, D 1992, Economic and technical feasibility for backfill design in Quebec underground mines, Final report 1/2, Canada-Quebec Mineral Development Agreement, Research \& Development in Quebec Mines, Contract no EADM 1989-1992, File-no. 71226002.

Hassani, FP \& Archibald, JF 1998, Mine backfill, Canadian Institute of Mining, Metallurgy and Petroleum, Montreal, Quebec, on CD-ROM.

Hassani, F, Razavi, M \& Isagon, I 2007, 'Strength Characteristics of Sodium Silicate-fortified Sand Pastefill', CIM Bulletin, vol. 2, no. 5, pp. 9.

Kermani, M, Hassani, F \& Isagon, I 2009, 'The effect of sodium silicate concentration and pulp density on the strength of gelfill', in RK Singhal, A Mehrotra, K Fytas and H Ge (eds), Proceedings of the 18th International Symposium on Mine Planning and Equipment Selection, Curran Associates, Inc., Red Hook, pp. 439-448, on CD-ROM.

Klassen, VI \& Mokrousov, VA 1963, An introduction to the theory of floatation, Butterworth Publishers, Oxford, Oxfordshire.

Lukaszewski, GM 1969, 'Natural oxidation and the reaction of ANFO explosives in mineral sulphides at Mount Isa Mines Ltd.', in MJ Jones (ed.), Proceedings of the 9th Commonwealth Mining and Metallurgical Congress, Institution of Mining and Metallurgy, London, pp. 33-49.

Navarra, A, Graham, JT, Somot, S, Ryan, DH \& Finch, JA 2010, 'Mössbauer quantification of pyrrhotite in relation to self-heating', Minerals Engineering, vol. 23, no. 8, pp. 652-8.

Ninteman, DJ 1978, 'Spontaneous oxidation and combustion of sulphide ores in underground mines: A literature survey', Information circular, U.S. Department of Interior, Bureau of Mines.

O'Brien, MM \& Banks, HR 1926, 'The Sullivan mine and concentrator: A review of 3 years progress', CIM Magazine, vol. 29, pp. 100-21.

Payant, RA 2010, 'The self-heating of sulphide mixtures', master thesis, McGill University.

Payant, RA \& Finch, JA 2010, 'The self-heating of sulphide mixtures', Canadian Metallurgical Quarterly, vol 49, no 4, pp. $429-434$.

Rosenblum, F \& Spira, P 1981, 'Self-heating of sulphides', Proceedings of the 13th Annual Meeting of the Canadian Mineral Processors, Canadian Institute of Mining, Metallurgy and Petroleum, Montreal, pp. 34-49.

Rosenblum, F \& Spira, P 1995, 'Evaluation of hazard from self-heating of sulphide rock', CIM Bulletin, vol. 88, no. 989, pp. 44-9.

Rosenblum, F, Nesset, JE \& Spira, P 2001, 'Evaluation and control of self-heating in sulphide concentrates', CIM Bulletin, vol. 94, no. 10,569 , pp. $92-9$

Somot, S \& Finch, JA 2010, 'Possible role of hydrogen sulphide gas in self-heating of pyrrhotite-rich materials', Mineral Engineering, vol. 23, no. 2, pp. 104-10.

Spearing, AJS \& Smart, RM 1990, 'The Potential benefits of (silicated) cemented backfill system', in DAI Ross-Watt and PDK Robinson, Proceedings of the International Deep Mining Conference, vol 2: Technical challenges in deep level mining, South African Institute of Mining and Metallurgy, Johannesburg.

Wang, X, Rosenblum, F, Nesset, JE, Somot, S \& Finch, JA 2009, 'Oxidation, weight gain and self-heating of sulphides', in R Henderson (ed.), Proceedings of the 41st Annual Meeting of the Canadian Mineral Processors, Canadian Institute of Mining, Metallurgy and Petroleum, Montreal, pp. 63-77.

$\mathrm{Wu}, \mathrm{C} \& \mathrm{Li}, \mathrm{Z}$ 2005, 'A simple method for predicting the spontaneous combustion potential of sulphide ores at ambient temperature', Mining Technology, Transactions of IMM, vol. 114, no. 2, pp. 125-8.

Zarassi, A, Hassani, F, Nesset, J, Rosenblum, F \& Isagon, I 2011, 'Self-heating and mitigating methods for minefill', in HJ Ilgner, Proceedings of the 10th International Symposium on Mining with Backfill, South African Institute of Mining and Metallurgy, Johannesburg, pp. 377-82. 